\title{
LEKSIKON ANYAMAN BAMBU \\ DI KECAMATAN PACET KABUPATEN BANDUNG (Kajian Etnolinguistik)
}

\author{
Puspa Endah Setiani, Yayat Sudaryat, Usep Kuswari \\ Program Studi Bahasa dan Budaya Sunda, Pascasarjana UPI \\ Pos-el: setianipuspaendah@gmail.com, yayat.sudaryat@upi.edu, \\ usep.kuswari@upi.edu
}

\begin{abstract}
Abstrak
Penelitian ini dilatarbelakangi oleh pentingnya mempertahankan tradisi, adat-istiadat, dan bahasa daerah yang merupakan kekayaan suatu bangsa. Anyaman bambu merupakan salah satu tradisi yang masih bertahan saat ini dalam himpitan kehidupan modern sangat penting untuk dilestarikan. Penelitian ini bertujuan untuk mengetahui leksikon anyaman bambu yang ada di Kecamatan Pacet Kabupaten Bandung. Metode yang digunakan adalah metode deskriptif melalui pendekatan kualitatif. Sumber data penelitian adalah para pengrajin anyaman bambu di Kecamatan Pacet Kabupaten Bandung. Instrumen yang digunakan untuk mengumpulkan data adalah wawancara dan observasi. Data yang sudah diperoleh dianalisis berdasarkan kajian etnolinguistik. Berdasarkan hasil penelitian yang sudah dilaksanakan, terdapat 19 leksikon anyaman bambu yang ada di kecamatan Pacet Kabupaten Bandung. Leksikon anyaman bambu tersebut diklasifikasikan berdasarkan fungsinya, yaitu (1) alat dapur, (2) alat rumah tangga, (3) alat pertanian, (4) alat perikanan, dan (5) alat bangunan rumah. Sedangkan berdasarkan kajian etnolinguistik, terdapat istilah-istilah anyaman awi yang mengandung nilai-nilai budaya yang tinggi yang erat hubunganna sistem kepercayaan yang ada pada masyarakat.
\end{abstract}

Kata Kunci: leksikon, anyaman bambu, etnolinguistik.

\section{THE LEXICON OF BAMBOO WOVEN IN PACET, BANDUNG DISTRICT (ETNOLINGUISTIC STUDY)}

\begin{abstract}
This research is motivated by the importance of maintaining traditions, customs, and regional languages, which constitute national property. Bamboo woven, one of the traditions that still survive today though under the pressure of modern life is very important to be preserved. This study aims to find out bamboo woven lexicon in Pacet of Bandung district. The method used was the descriptive method with a qualitative approach. The source of the research data is bamboo woven craftsmen in Pacet, Bandung District. The instrument used to collect data was interviews and observations. The data obtained was analyzed based on ethnolinguistic studies. Based on the results of the research, there are 19 woven bamboo lexicons. The lexicon of woven bamboo is classified based on its functions, i.e. (1) kitchen utensils, (2) household appliances, (3) agricultural tools, (4) fishing equipment, and (5) house building tools. Whereas based on ethno-linguistic studies, there are woven terms that contain high cultural values that are closely related to the belief system that exists in society.
\end{abstract}

Keywords: lexicon, bamboo woven, ethno-linguistics. 


\section{PENDAHULUAN}

Indonesia adalah suatu negara yang memiliki keanekaragaman suku bangsa. Setiap suku bangsa memiliki tradisi, adat-istiadat, dan bahasa yang merupakan kekayaan suatu bangsa. Tapi sejalan dengan perkembangan jaman dan arus modernsasi, terdapat pengaruh dan perubahan terhadap tradisi, adat-istiadat, dan bahasa yang bisa berakibat menghilangnya tradisi, adat-istiadat, dan bahasa tersebut sebagai ciri utama suatu suku bangsa Indonesia.

Bahasa tidak dapat dipisahkan dari kehidupan manusia. Sebagai makhluk sosial, manusia tidak dapat hidup sendiri. Hal ini sejalan dengan pendapat Damaianti (2011) yang menyatakan bahwa manusia adalah makhluk sosial yang bergantung pada bahasa sebagai sarana komunikasi dan interaksi. Melalui bahasa manusia bisa memberi dan mendapatkan informasi yang berguna untuk mempertahankan keberadaannya di masyarakat.

Perkembangan suatu bahasa bisa ditentukan oleh loyalitas pengguna bahasa tersebut. Terdapat empat komponen yang bertanggung jawab terhadap perkembangan bahasa, yaitu para ahli bahasa, pemerintah, guru bahasa, dan masyarakat pengguna bahasa tersebut (Pramesti, 2015).

$\begin{array}{ccc}\text { Berdasarkan penelitian } & \text { yang } \\ \text { dilakukan oleh } & \text { Lembaga } & \text { Ilmu }\end{array}$ Pengetahuan Indonesia (LIPI) pada tahun 2016, di Indonesia terdapat 139 bahasa daerah yang terancam punah. Dari 617 bahasa daerah yang telah teridentifikasi oleh Badan Bahasa Kemendiknas, sebanyak 15 bahasa daerah statusnya dinyatakan punah. Kepunahan suatu bahasa daerah bisa disebabkan oleh empat faktor. Pertama, para penuturnya berpikir tentang dirinya sebagai inferior secara sosial dan kedua karena keterikatan pada masa lalu. Ketiga, isi tradisional dan keempat karena secara ekonomi kehidupannya stagnan. Keempat sebab ini oleh para linguis disebut sebagai proses penelantaran bahasa (lipi.go.id/lipimedial diakses 28 Agustus 2017).

Selain kemampuan berbahasa, manusia juga dapat menggunakan dan mengembangkan pikiran dan perasaannya. Dalam kehidupan sehari-hari, manusia tumbuh dan berkembang dengan budayanya. Pada hakikatnya, budaya mempunyai nilai-nilai yang diwariskan, ditafsirkan, dan dilaksanakan sesuai dengan proses perubahan sosial masyarakat.

Budaya adalah pikiran, akal budi atau hasil adat-istiadat. Sedangkan kebudayaan bisa maknai sebagai hasil dari pemikiran manusia. Kebudayaan juga dapat dimaknai sebagai suatu peradaban yang terdiri dari pemahaman suatu bangsa yang kompleks, pengetahuan, kapercayaan, seni, moral, hukum, adat-istiadat (kabiasaan), dan hal-hal lainnya yang ada dalam suatu masyarakat (Taylor dalam Soelaeman, 2010, hlm. 19)

Suku Sunda terkenal dengan berbagai kebudayaan tradisionalnya, dari mulai adat-istiadat yang ada dalam keluarga hingga yang ada dalam lingkungan masyarakat. Alam bagi masyarakat Sunda merupakan suatu tempat yang menyediakan berbagai macam sumber daya untuk dikelola dengan baik. Sebagai salah satu wujud dari pengelolaan sumber daya alam tersebut masyarakat Sunda menjadikan tanaman bambu sebagai bahan dasar dari kerajinan, yaitu anyaman bambu.

Anyaman merupakan suatu kesenian tradisional yang masih bertahan hingga saat ini. Di jaman modern seperti sekarang ini, sudah banyak perubahan yang terjadi pada perkembangan anyaman, baik dari segi bentuk maupun dari segi motif anyamannya.

Prabawati (2016) menjelaskan bahwa anyaman adalah wujud kebudayaan yang termasuk ke dalam 
artefak. Artefak adalah wujud kebudayaan fisik yang berupa hasil dari aktivitas, perilaku, dan karya manusia yang berupa benda-benda atau hal-hal lain yang bisa diraba, dilihat, dan didokumentasikan.

Sedangkan bambu adalah tumbuhan yang termasuk ke dalam jenis rumput-rumputan yang batangnya mempunyai rongga dan ruas. Bambu juga merupakan salah satu kekayaan alam yang mempunyai potensi dan dapat dimanfaatkan untuk memenuhi kebutuhan manusia. Pada jaman dahulu, masyarakat mampu memberdayakan tumbuhan bambu untuk memenuhi kebutuhan mereka dalam kehidupan sehari-hari, seperti kebutuhan sandang, pangan, dan papan. Tapi pada jaman modern ini, pemberdayaan tumbuhan bambu sudah mulai menurun. Hal ini dikarenakan adanya perubahan jaman yang lebih maju dan canggih. Salah satu pemberdayaan bambu pada jaman sekarang ini adalah dengan membuat kerajinan anyaman bambu yang merupakan kerajinan tradisional Indonesia.

Anyaman bambu merupakan salah satu hasil karya seni asli Indonesia yang dikembangkan secara turun-temurun sebagai sumber penghasilan dan kehidupan rakyat (Gerbono \& Siregar, 2009, hlm. 3).

Anyaman bambu bisa disebut sebagai kebudayaan etnik karena merupakan salah satu kebudayaan atau tradisi suku bangsa yang masih dipeliraha oleh masyarakatnya hingga kini. Selain itu, tradisi anyaman bambu juga merupakan kebudayaan yang masih asli dan belum tercampuri oleh budaya asing.

Etnolinguistik adalah ilmu yang meneliti seluk beluk hubungan aneka pemakaian bahasa dengan pola kebudayaan dalam masyarakat tertentu, atau ilmu yang mencoba mencari hubungan antara bahasa, penggunaan bahasa dan kebudayaan pada umumnya. Menurut Kridalaksana (2008, hlm. 59), etnolinguistik adalah cabang linguistik yang menyelidiki hubungan antara bahasa dan masyarakat pedesaan atau masyarakat yang belum mempunyai tulisan, atau cabang ilmu linguistik yang menyelidiki hubungan bahasa dan sikap bahasawan terhadap bahasa.

Bahasa erat kaitannya dengan kebudayaan karena keduanya saling mempengaruhi. Hal yang menjadi dasar dalam hubungan antara bahasa dengan kebudayaan adalah bahasa harus ada dalam konteks kebudayaan, sedangkan kebudayaan bisa muncul melalui bahasa (Ayu, 2014).

Istilah etnolinguistik muncul ketika para ahli antropologi mulai melakukan penelitian yang lebih mendalam dan profesional dalam disiplin ilmu antropologi. Istilah ini dibentuk dari gabungan antara dua kata, yaitu kata etnologi dan linguistik. Etnologi atau antropologi budaya adalah ilmu yang mempelajari mengenai suku-suku tertentu. Sedangkan linguistik adalah ilmu yang mempelajari mengenai bahasa sehari-hari manusia, disebut juga ilmu bahasa.

Etnolinguistik adalah ilmu yang meneliti hubungan antara pangguna bahasa dengan pola kebudayaan masyarakat tertentu atau ilmu yang mempelajari hubungan antara bahasa, penggunaan bahasa, dan kebudayaan secara umum (Kamsiadi, dkk., 2013).

Banyak penelitian yang menggunakan kajian etnolinguistik dalam meneliti hubungan antara bahasa dan budaya. Penelitian ini dilaksanakan untuk menindaklanjuti penelitian-penelitian sebelumnya mengenai kajian etnolinguistik, khususnya dalam leksikon anyaman bambu di Kecamatan Pacet, Kabupaten Bandung.

Berdasarkan latar belakang di atas, maka masalah dalam penelitian ini dapat dirumuskan mengenai klasifikasi leksikon anyaman bambu dan unsur etnolinguistik leksikon anyaman bambu di Kecamatan Pacet Kabupaten Bandung. 
Penelitian ini diharapkan dapat memberikan manfaat yaitu memberikan sumbangsih untuk ilmu kebahasaan dan kebudayaan, khususnya bahasa dan budaya Sunda. Selain itu, penelitian ini juga diharapkan dapat memberi manfaat bagi masyarakat umum sehingga bisa menumbuhkan sikap untuk melestarikan bahasa dan budaya Sunda.

\section{METODE}

Penelitian ini menggunakan pendekatan kualitatif. Hal ini dikarenakan pendekatan kualitatif lebih sesuai dengan kondisi budaya yang merupakan cabang ilmu humaniora yang bersifat unik. Sejalan dengan hal tersebut, dalam penelitian ini digunakan metode deskriptif. Fathoni (2006, hlm. 97) menerangkan bahwa metode deskriptif adalah penelitian yang bermaksud untuk mengadakan pemeriksaan dan pengukuran- pengukuran terhadap suatu kejadian tertentu.

Metode penelitian pada dasarnya dibagi atas tiga tahap, yaitu (a) tahap penyediaan data, (b) tahap analisis data, dan (c) tahap penyajian data. Metode penyediaan data yang digunakan dalam penelitian ini adalah metode simak, yaitu dengan menyimak pembicaraan dengan mewawancarai informan yang sudah dipilih dan mengerti tentang leksikon anyaman bambu di Kecamatan Pacet, Kabupaten Bandung.

Kemudian peneliti teknik rekam dan teknik catat. Dalam hal ini peneliti merekam semua kata-kata yang muncul dari informan dan mencatat data yang telah direkam. Lalu peneliti memilah dan memilih data yang dibutuhkan. Apabila data sudah terkumpul kemudian dianalisis dengan cara diklasifikasikan berdasarkan fungsinya.

Metode selanjutnya adalah metode deskriptif analisis, yaitu metode penelitian yang berusaha menggambarkan dan menginterpretasi objek sesuai dengan apa adanya (Aries, 2010, hlm. 25). Dalam penelitian ini, metode tersebut dilakukan dengan mendeskripsikan leksikon anyaman bambu di Kecamatan Pacet, Kabupaten Bandung. Metode analisis data dalam penelitian ini menggunakan metode padan ekstralingual. Hal ini dikarenakan, peneliti menghubungkan bahasa dengan hal yang di luar bahasa, yaitu budaya.

Lokasi penelitian ini dilaksanakan di empat kampung yang ada di Desa Cikitu, Kecamatan Pacet, Kabupaten Bandung, di antaranya kampung Betah, Cikitu, Nenggeng, dan kampung Pamoyanan. Kampung-kampung tersebut merupakan kampung yang mayoritas masyarakatnya adalah pengrajin anyaman bambu.

\section{HASIL DAN PEMBAHASAN}

Menurut Riana (dalam Ayu, 2014) linguistik kebudayaan adalah sebuah studi yang meneliti hubungan intrinsik antara bahasa dan budaya, bahasa dipandang sebagai fenomena budaya yang kajiannya berupa language in cultural atau language and cultural. Objek kajian penelitiannya berupa daftar kata-kata, pelukisan dari ciri-ciri, dan pelukisan dari tata bahasa dan bahasa-bahasa lokal.

Berdasarkan beberapa pengertian tentang etnolunguistik, yang intinya menerangkan bahwa etnolinguistik adalah studi mengenai fenomena kebahasaan dalam kebudayaan masarakat penuturnya, bisa dirumuskan secara singkat bahwa bidang talaah etnolinguistik yaitu fenomena kebahasaan yang berkaitan dengan unsur-unsur budaya yang dikemukakan oleh Koentjaraningrat (dalam Baehaqi, 2013, hlm. 8), di antaranya bahasa, sistem pengetahuan, sistem organisasi sosial, sistem perkakas dan teknologi, sistem mata pencaharian, sistem kepercayaan, dan kesenian.

Konsepsi dapat terbentuk melalui budaya dengan menunjukkan adanya pola pikir masyarakat dalam mendeskripiskan leksikon anyaman bambu di kecamatan 
Pacet, kabupaten Bandung. Hal ini sejalan dengan teori Sibarani (2004, hlm. 57) bahwa hubungan bahasa dengan kebudayaan bisa dikaitkan. Selain itu, bahasa merupakan hasil kebudayaan, karena peran bahasa sangat penting untuk mengarahkan pikiran manusia. Pengarah pikiran ini akan lebih efektif lagi apabila pembicara menggunakan kemampuan berbahasa, kemampuan komunikasi, dan kemampuan retorika.

Berdasarkan hal tersebut, artinya bahasa dalam hal ini disebut leksikon yang dipergunakan atau diucapkan oleh suatu kelompok masyarakat adalah suatu refleksi atau cermin keseluruhan kebudayaan masyarakat tersebut.

Leksikon berasal dari kata Yunani Kuno, yaitu lexicon yang berarti kata, ucapan, atau cara berbicara (Chaer, 2007:6). Setiap sendi kehidupan tentu memiliki leksikon khas yang menyertainya. Dari hasil penelitian, data yang terkumpul sebanyak 19 leksikon anyaman bambu.

Leksikon-leksikon tersebut dapat diklasifikasikan berdasarkan fungsinya, yaitu (1) alat dapur, (2) alat rumah tangga, (3) alat pertanian, (4) alat perikanan, dan (5) alat bangunan rumah.

\section{Leksikon dalam Alat Dapur}

Terdapat 12 leksikon anyaman bambu yang merupakan alat dapur, yaitu leksikon aseupan, ayakan, boboko, boboko turub, cécémpéh, dingkul, hihid, nyiru, pipiti, tampir, téténong, dan tolombong.

\section{Aseupan}

Aseupan adalah wadah dari anyaman bambu, bentuknya seperti kerucut, digunakan untuk menanak nasi atau mengukus makanan yang lainnya (Danadibrata, 2009, hlm. 36). Biasanya aseupan digunakan bersamaan dengan sééng, yaitu alat yang terbuat dari tembaga atau seng yang digunakan untuk memasak air, menanak nasi atau mengukus makanan lainnya.
Masyarakat Sunda, khususnya di Kecamatan Pacet mempunyai kepercayaan bahwa aseupan merupakan simbol dalam kehidupan beragama. Bentuk aseupan yang berbentuk kerucut dipercaya bahwa bagian bawah dari aseupan melambangkan hubungan manusia dengan manusia dan bagian kerucutnya melambangkan hubungan manusia dengan Tuhannya.

Selain itu, masyarakat juga mempercayai bahwa aseupan tidak boleh (pamali) digunakan sebagai topi, khususnya bagi anak-anak dan orang dewasa yang belum menikah. Hal tersebut dipercaya bisa mengakibatkan susah mendapatkan jodoh.

\section{Ayakan}

Leksikon ayakan berasal dari kata ayak, yaitu kegiatan memisahkan antara benda-benda yang halus dengan yang kasar menggunakan alat, seperti tepung semen bata, bubuk kopi, dan lain-lain. Sedangkan ayakan adalah alat yang digunakan untuk mengayak (Danadibrata, 2009, hlm. 42).

Anyaman ayakan berbentuk bulat, menggunakan wengku, serta anyamannya jarang. Bentuk ayakan yang bulat bisa memberi gambaran bahwa masyarakat Sunda harus mempunyai keinginan, niat dan tekad yang bulat. Bentuk bulat dipercaya erat kaitannya dengan sikap mental, pikiran, dan perilaku orang Sunda. Selain itu, bentuk bulat juga dipercaya sebagai perlambang dari kesempurnaan.

Salian bentuk bulat, anyaman ayakan juga dianyam dengan teknik anyaman jarang. Sesuai dengan fungsinya yaitu sebagai pemisah antara benda halus dan kasar. Perkakas ayakan dipercaya masyarakat sebagai simbol dalam kehidupan sosial yaitu melambangkan bahwa manusia harus bisa memilih dan memisahkan antara yang baik dan yang buruk. 


\section{Boboko}

Boboko adalah wadah yang terbuat
dari anyaman bambu dengan menggunakan soko dan wengku (Danadibrata, 2009, hlm. 98). Bagian atas dari boboko berbentuk bulat dan agak besar, sedangkan bagian bawahnya berbentuk persegi dan agak kecil serta menggunakan soko agar dapat berdiri tegak.

Bentuk bulat pada anyaman boboko dipercaya erat kaitannya dengan sikap mental, pikiran, dan perilaku orang Sunda. Selain itu, bentuk bulat juga dipercaya sebagai perlambang dari kesempurnaan. Selain bentuk bulat, boboko juga berbentuk persegi di bagian bawahnya atau biasa disebut soko. Bentuk persegi bisa memberi gambaran bahwa hidup ini harus masagi, artinya manusia harus menjalani kehidupannya secara seimbang. Biasanya diterapkan dalam perkara menjalani kehidupan di dunia dan akhirat. Selain itu, bentuk persegi juga dipercaya bahwa kehidupan manusia dalam segala bidang harus dijalani secara seimbang. Misalnya, manusia yang hidup di dunia, selain harus memikirkan keperluan hidup di dunia, juga harus mengumpulkan amal ibadah sebagai bekal di akhirat.

\section{Boboko turub}

Boboko turub hampir serupa dengan boboko. perbedaan antara keduanya adalah boboko biasa tidak disertai dengan turub (penutup), sedangkan boboko turub disertai dengan turub (penutup) pada bagian atasnya sehingga bisa menutupi makanan dari debu dan kotoran.

Fungsi wengku dalam anyaman boboko turub yaitu sebagai penguat bibir, baik anyaman bobokonya maupun anyaman turubnya, agar anyaman agar tidak mudah lepas dan rusak. Sedangkan dalam kehidupan, wengku dilambangkan sebagai penjaga agar manusia bisa berbicara dengan baik dan benar.

\section{Cécémpéh}

Cécémpéh adalah alat atau wadah sejenis nyiru yang ukurannya lebih kecil (Hidayat, dkk., 2007, hlm. 26). Cécémpéh terbuat dari anyaman bambu, bentuknya bulat disertai dengan wengku. Cécémpéh biasanya digunakan untuk menyimpan bumbu atau makanan.

Dalam kehidupan masyarakat Sunda, biasanya cécémpéh digunakan sebagai wadah untuk menyimpan nasi tumpeng dalam acara syukuran. Hal ini menunjukkan bahwa cécémpéh adalah salah satu alat yang bisa digunakan sebagai ungkapan rasa syukur kepada Pencipta.

\section{Dingkul}

Dingkul adalah alat atau wadah yang terbuat dari anyaman bambu, bentuknya persegi di bagian bawah dan bulat di bagian atas serta di bagian sisinya menggunakan wengku (Danadibrata, 2009, hlm. 171).

Dingkul biasanya digunakan sebagai wadah untuk menyimpan beras atau padi. Bentuk dingkul yang bulat di bagian atasnya menunjukkan bahwa masyarakat Sunda mempunyai tekad yang bulat dan kuat. Selain bentuknya yang bulat, dingkul juga dilengkapi dengan wengku sebagai penguat bibir anyaman agar tidak mudah lepas dan rusak. Sedangkan dalam kehidupan, wengku dilambangkan sebagai penjaga agar manusia bisa berbicara dengan baik dan benar.

\section{Hihid}

Hihid adalah alat yang dipakai untuk mengipasi nasi yang sedang diaduk (Danadibrata, 2009, hlm. 256). Hihid berbentuk persegi empat dengan pegangan yang terbuat dari bambu juga. Selain mengipasi nasi, hihid juga bisa dipakai untuk mengipasi bara api atau mengipasi makanan yang dimasak dengan cara dibakar.

Sebagai alat pengipas nasi, hihid berfungsi untuk mengdinginkan nasi yang panas. Sedangkan sebagai pengipas 
bara api, hihid berfungsi untuk menyalakan api. Hal ini bisa memberi gambaran bahwa sebagai manusia, kita harus bisa mengatur sikap. Sikap yang baik terhadap sesama manusia bisa meredam pertengkaran dan permusuhan. Sedangkan sikap yang buruk terhadap sesama bisa memicu perpecahan dan permusuhan.

\section{Nyiru}

Nyiru adalah alat yang digunakan untuk menumbuk yang terbuat dari anyaman bambu (Danadibrata, 2009, hlm. 469). Nyiru juga biasa digunakan untuk membersihkan beras, kacang hijau, dan lain-lain dari kotoran dan debu. Bentuk dari nyiru adalah bulat, datar, dan disertai dengan wengku.

Selain cécémpéh, nyiru juga biasa dipakai masyarakat sebagai wadah untuk menyimpan nasi tumpeng dalam acara syukuran. Hal ini menunjukkan bahwa nyiru adalah salah satu alat yang bisa digunakan sebagai ungkapan rasa syukur kepada Pencipta.

\section{Pipiti}

Pipiti adalah wadah yang terbuat dari anyaman bambu dan mempunyai penutup yang sama bentuknya (Danadibrata, 2009, hlm. 534). Biasanya pipiti mempunyai ukuran $20 \times 20 \times 5 \mathrm{~cm}$. Pipiti biasa digunakan sebagai wadah untuk menyimpan nasi dengan lauk pauknya dan dibagikan sebagai bingkisan.

Pipiti sangat berpengaruh dalam kehidupan sosial masyarakat. Pipiti merupakan salah satu alat yang digunakan untuk mempererat tali silaturahmi di antara warga masyarakat. Selain itu pipiti juga merupakan simbol dari kebaikan masyarakat Sunda dengan cara berbagi dengan sesama.

\section{Tampir}

Tampir adalah nyiru yang ukurannya lebih besar dan anyamannya kasar (Danadibrata, 2009, hlm. 675). Tampir biasanya digunakan untuk menjemur opak, padi, dan lain sebagainya.

Cara menggunakan tampir biasanya disimpan di tempat yang panas agar terkena sinar matahari, kemudian simpan bahan makanan untuk dijemur. Hal ini mencerminkan bahwa orang Sunda pandai beradaptasi dengan alam.

\section{Téténong}

Téténong adalah wadah yang digunakan untuk menyimpan makanan yang sudah matang (Danadibrata, 2009, hlm. 690). Biasanya téténong berbentuk bulat, disertai dengan penutup di bagian atas dan soko di bagian bawah.

Téténong digunakan sebagai wadah makanan yang sudah matang yang kemudian ditutup dengan penutupnya. Hal ini menunjukkan bahwa masyarakat Sunda, khususnya di kecamatan Pacet, sangat mementingkan kebersihan, karena kebersihan merupakan sebagian dari iman. Selain itu, masarakat Sunda juga mementingkan kesehatan, makanan yang ada dalam téténong dijaga dan ditutup dengan rapi agar terhindar dari debu dan kotoran lainnya.

\section{Tolombong}

Tolombong adalah dingkul yang anyamannya jarang, biasa disebut talombong (Danadibrata, 2009, hlm. 706). Tolombong berbentuk bulat di bagian atas dan persegi empat di bagian bawah. Biasanya digunakan sebagai wadah padi, beras, dan sebagainya.

Fungsi tolombong sebagai tempat penyimpanan menunjukkan bahwa manusia hidup di dunia harus bisa menyimpan atau menabung keperluannya untuk kehidupan di masa yang akan datang.

\section{Leksikon Alat Rumah Tangga}

Terdapat dua leksikon anyaman bambu yang merupakan alat rumah tangga, yaitu leksikon carangka dan pengki. 


\section{Carangka}

Carangka adalah keranjang yang anyamannya jarang (Danadibrata, 2009, 130). Bentuknya bulat dan besar, biasanya digunakan sebagai tempat sampah.

Penggunaan carangka sebagai tempat sampah menunjukkan bahwa masyarakat Sunda, khususnya masyarakat di Kecamatan Pacet sangat menjaga kebersihan lingkungan alamnya. Hal ini menunjukkan bahwa orang Sunda sangat menjaga dan mencintai lingkungan alamnya dengan baik.

\section{Pengki}

Pengki adalah alat yang digunakan untuk mengambil sampah yang sudah dikumpulkan (Danadibrata, 2009, hlm. 520). Selain dari bambu yang dianyam, pengki juga ada yang terbuat dari plastik dengan pegangan agar dapat dengan mudah dipegang. Pengki juga bisa terbuat dari kaleng bekas yang dipotong diagonal.

Penggunaan pengki sebagai perkakas yang digunakan untuk membersihkan sampah merupakan wujud kecintaan masyarakat terhadap lingkungan alamnya.

\section{Leksikon Alat Pertanian}

Terdapat dua leksikon anyaman bambu yang merupakan alat pertanian, yaitu dudukuy dan giribig.

\section{Dudukuy}

Dudukuy adalah penghalang dari panas dan hujan yang dipasang di atas kepala (Danadibrata, 2009, hlm. 176). Dudukuy bisa disebut sebagai penutup kepala atau topi. Dibuat dari anyaman bambu, bentuknya bulat dan mengerucut di bagian atasnya. Hampir sama dengan aseupan, tetapi dudukuy lebih pendek dan lebih lebar daripada aseupan.

Dudukuy sangat berfungsi ketika petani bekerja disaat cuaca panas maupun hujan. Hal ini menunjukkan bahwa sikap masyarakat Sunda itu pantang menyerah dalam keadaan apapun. Masyarakat tetap mampu bekerja dalam situasi apapun.

\section{Giribig}

Giribig adalah anyaman bambu yang serupa dengan bilik, tetapi mempunyai anyaman yang lebih kecil (Danadibrata, 2009, hlm. 229). Giribig biasanya digunakan sebagai alas untuk menjemur padi, kacang tanah, dan lain-lain. Selain itu, giribig juga bisa digunakan sebagai langit-langit rumah.

Cara menggunakan girirbig biasanya disimpan di tempat yang panas agar terkena sinar matahari, kemudian simpan hasil panen berupa padi untuk dijemur. Hal ini mencerminkan bahwa orang Sunda pandai beradaptasi dengan alam, khususnya ketika melaksanakan aktivitas yang berkaitan dengan pertanian.

\section{Leksikon Alat Perikanan}

Terdapat dua leksikon anyaman bambu yang merupakan alat perikanan, yaitu bubu dan sair.

\section{Bubu}

$B u b u$ adalah alat yang digunakan untuk menangkap ikan di perairan yang mengalir (Danadibrata, 2009, hlm. 106). $B u b u$ terbuat dari bambu yang dianyam. Biasanya $b u b u$ dipasang di sungai untuk menangkap ikan.

Hal ini menunjukkan bahwa dalam setiap kehidupan diperlukan usaha untuk mendapatkan apa yang diinginkan. Sama halnya dengan penggunaan bubu. Bubu dibuat dengan baik sehingga bisa digunakan dengan baik pula untuk mendapatkan atau menangkap ikan.

Sair

Sair adalah alat untuk menangkap ikan (Danadibrata, 2009, hlm. 596). Bentuk sair hampir sama dengan ayakan, tetapi dengan anyaman yang lebih rapat. Sair biasa digunakan untuk menangkap ikan di kolam.

Bentuk sair yang bulat menunjukkan sikap dan tekad masyarakat Sunda yang 
bulat dan sempurna. Sedangkan anyaman sair yang jarang menunjukkan bahwa dalam setiap menjalani kehidupan harus bisa memilah dan memilih mana yang baik dan yang buruk sehingga bisa mendapatkan hasil yang baik yang sesuai dengan yang diinginkan.

\section{Leksikon Alat Bangunan Rumah}

Terdapat satu leksikon anyaman bambu yang merupakan alat bangunan rumah yaitu bilik.

Bilik adalah anyaman kepang dari bambu yang dipotong tipis yang digunakan sebagai dinding rumah (Danadibrata, 2009, hlm. 93). Bilik kepang biasanya dianyam dengan sudut $90^{\circ}$.

Bilik yang digunakan sebagai dinding rumah merupakan hal yang menunjukkan adanya hubungan yang baik antara manusia dan alam. Pemanfaatan bambu yang digunakan sebagai bilik dipercaya sebagai tanda bukti rasa syukur manusia kepada Tuhannya.

\section{SIMPULAN}

Berdasarkan hasil penelitian, dapat disimpulkan bahwa leksikon anyaman bambu yang ada di Kecamatan Pacet, Kabupaten ada 19 leksikon. Semua leksikon tersebut merupakan produk-produk anyaman bambu yang diproduksi oleh masyarakat Kecamatan Pacet, Kabupaten Bandung.

Leksikon anyaman bambu di Kecamatan Pacet, Kabupaten Bandung dapat diklasifikasikan berdasarkan fungsinya. Berdasarkan fungsinya, leksikon anyaman bambu di Kecamatan Pacet, Kabupaten Bandung dapat diklasifikasikan ke dalam lima fungsi, yaitu sebagai alat dapur, alat rumah tangga, alat pertanian, alat perikanan, dan alat bangunan rumah.

Deskripsi leksikon anyaman bambu di Kecamatan Pacet, Kabupaten Bandung, terdapat 19 data leksikon dan semua berkategori nomina.
Leksikon-leksikon anyaman bambu tersebut terdapat dalam Kamus Basa Sunda R.A. Danadibrata. Selain itu, leksikon anyaman bambu juga dapat dideskripsikan sesuai dengan fungsinya sebagai bagian dari kebudayaan.

Selanjutnya berkaitan dengan hasil penelitian tersebut, maka disarankan perlu dilaksanakan penelitian lanjutan ihwal tradisi atau kebudayaan anyaman bambu. Hal ini dilaksanakan agar ke depan tradisi atau kebudayaan anyaman bambu bisa tetap bertahan dan tidak tergerus oleh kemajuan jaman. Selain itu, diharapkan pula tradisi menganyam bambu juga bisa terus berkembang sesuai dengan perubahan jaman.

\section{PUSTAKA RUJUKAN}

Aries, Erna Febru. (2010). Design Action Research. Yogyakarta: Aditya MediaPublising.

Ayu, N. P. (2014). Konsep hidup dan mati dalam leksikon khaul buyut tambi (kajian etnolinguistik di Indramayu). Jurnal Bahtera Sastra: Antologi Bahasa dan Sastra Indonesia, (1).

Baehaqie, I. (2013). Etnolinguistik: Telaah teoritis dan praktis. Surakarta: Cakrawala Media.

Chaer, A. (2007). Leksikologi dan Leksikografi Indonesia. Jakarta: Rineka Cipta.

Damaianti, V. S. (2011). Pola sintaksis dan semantis dalam wacana sastra dan wacana ilmiah serta keterpahamannya. Jurnal Metalingua: Jurnal Penelitian Bahasa, 9 (2).

Danadibrata, R. A. (2009). Kamus basa Sunda. Bandung: PT. Kiblat Buku Utama.

Fathoni, A. (2006). Metode penelitian dan teknik penyusunan skripsi. Jakarta: Rineka Cipta. 
Gerbono, A. \& Abbas S. (2009). Aneka anyaman bambu. Yogyakarta: Kanisius.

Hidayat, R.T., dkk. (2007). Peperenian urang sunda. Bandung: PT. Kiblat Buku Utama.

Kamsiadi, B. F., spk. (2013). Istilah-istilah yang digunakan pada acara ritual petik pari oleh masyarakat Jawa di desa Sumberpucung kabupaten Malang (Kajian etnolinguistik). Jurnal Publika Budaya, 1 (1), hlm. 64-78.

Kridalaksana, H. (2008). Kamus Linguistik. Jakarta: Gramedia Pustaka Utama.

lipi.go.id/lipimedia/139-bahasa-daerah-di -indonesia-terancam-punah (online) (28 Agustus 2017)

Pramesti, U. D. (2015). Peningkatan penguasaan kosakata bahasa Indonesia dalam keterampilan membaca melalui teka-teki silang (Penelitian tindakan di kelas VI
SD Surakarta 2, kecamatan Suranenggala, kabupaten Cirebon, Jawa Barat). Jurnal Puitika, 11 (1), hlm. 82-93.

Prabawati, M. N. (2016). Etnomatematika masyarakat pengrajin anyaman Rajapolah kabupaten Tasikmalaya. Jurnal Infinity: Jurnal Ilmiah Program Studi Matematika STKIP Siliwangi Bandung, 5 (1), hlm. 25-31.

Sibarani,R. (2004). Antropolinguistik. Medan: Poda.

Soelaeman, M. (2010). Ilmu budaya dasar suatu pengantar. Bandung: PT. Refika Aditama.

\section{UCAPAN TERIMA KASIH}

Terima kasih penulis sampaikan kepada semua pihak yang telah membantu penelitian ini, terutama kepada Penyunting Jurnal Lokabasa atas dimuatnya tulisan ini 